\title{
Correction to "Modeling Corticosteroid Pharmacokinetics and Pharmacodynamics, Part II: Sex Differences in Methylprednisolone Pharmacokinetics and Corticosterone Suppression"
}

\author{
In the above article [Ayyar VS, DuBois DC, Nakamura T, Almon RR, and Jusko WJ (2019) \\ $J$ Pharmacol Exp Ther, 370(2): 327-336; DOI: https://doi.org/10.1124/jpet.119.257527], the \\ following funding information was omitted:
}

This work was supported by the National Institutes of Health National Institute of General Medical Sciences [Grants GM24211 and GM131800].

The HTML and PDF versions of the article have been updated to include this information. The authors regret this error and any inconvenience it may have caused. 